\title{
ICDAS and dmft/DMFT. Sensitivity and specificity, the importance of the index used: a systematic review
}

\author{
ICDAS y ceod/COPD. Sensibilidad y \\ especificidad, la importancia del índice \\ utilizado: una revisión sistemática
}

Marcial Andrés Guiñez Coelho

Dental clinic GAMASmile (Santiago). Chile. marcial.guinezc@gmail.com

\begin{abstract}
INTRODUCTION: untreated dental caries is the most prevalent chronic disease in adults and untreated caries in deciduous teeth is the tenth most frequent chronic disease. Most of the studies do not present a representative population and there are no comparative studies between Decay - Missing - Filled in permanent teeth (dmft/DMFT) and International Caries Detection and Assessment System (ICDAS). We will seek to evaluate if there are differences in sensitivity and specificity in the diagnosis of caries using the ICDAS and dmft/DMFT index. OBJECTIVES: the objective of the investigation is to evaluate if there are differences in the sensitivity and specificity in the detection of caries using the ICDAS and dmft/DMFT indexes. METHODS AND MATERIALS: a qualitative systematic review was performed, searching the dmft/DMFT caries index and ICDAS in the Medline, ClinicalKey and SciELO databases, finding 3,581 of which 21 were read in full and 14 met the inclusion and exclusion criteria. RESULTS: The sensitivity and specificity are higher with ICDAS than with the dmft/DMFT index and provides up to $43 \%$ more information when detecting noncavitated lesions, but requires more time and resources due to the use of light, compressed air and pre-examination prophylaxis. Previous training, knowledge and experience in ICDAS are fundamental for the best result, studies showed that the more experience the sensitivity and specificity increased, unlike the dmft/DMFT index, although ICDAS was easy to understand by inexperienced professionals. CONCLUSION: more comparative studies between both indexes should be carried out and include ICDAS in children due to their ability to detect non-cavitated lesions which are the most prevalent in temporary teeth.
\end{abstract}

KEYWORDS: Dental caries. DMF index. Dental health surveys. Sensitivity and specificity.
RESUMEN | INTRODUCCIÓN: la caries dental no tratada es la enfermedad crónica más prevalente en adultos y la caries no tratada en dientes temporales es la décima enfermedad crónica más frecuente. La mayoría de los estudios no presentan una población representativa; además, no existen estudios comparativos entre el índice de dientes Cariados - Perdidos - Obturados (ceod/COPD) y el Sistema Internacional de Detección y Evaluación de Caries (ICDAS). Buscaremos evaluar si existen diferencias de sensibilidad y especificidad en el diagnóstico de caries utilizando ICDAS y el índice ceod/COPD. OBJETIVOS: el objetivo de la investigación es evaluar si existen diferencias en la sensibilidad y especificidad en la detección de caries entre los índices ICDAS y ceod/COPD. MATERIALES $\mathbf{Y}$ MÉTODOS: se realizó una revisión sistemática cualitativa, sobre el índice de caries ceod/COPD e ICDAS en las bases de datos de Medline, ClinicalKey y SciELO, encontrando 3.581 artículos de los cuales 21 fueron leídos íntegramente y 14 cumplieron los criterios de inclusión y exclusión. RESULTADOS: la sensibilidad y especificidad son mayores con ICDAS que con el índice ceod/COPD y proporciona hasta un 43\% más de información al detectar lesiones no cavitadas, pero requiere más tiempo y recursos debido al uso de luz, aire comprimido y profilaxis previa al examen. La formación previa, el conocimiento y la experiencia en ICDAS son fundamentales para el mejor resultado, los estudios demostraron que a mayor experiencia aumentaba la sensibilidad y especificidad, a diferencia del índice ceod/COPD, aunque ICDAS era fácil de entender por profesionales sin experiencia. CONCLUSIóN: se deben realizar más estudios comparativos entre ambos índices e incluir ICDAS en niños por su capacidad para detectar lesiones no cavitadas que son las más prevalentes en dientes temporales.

PALABRAS-CLAVE: Dental caries. DMF index. Dental health surveys. Sensitivity and specificity. 


\section{Introduction}

Worldwide, untreated caries disease is the most prevalent chronic pathology, even in temporary teeth it is the tenth most prevalent $t^{1-5}$. This evidence demonstrates the importance of knowing its pathophysiology, along with establishing public health policies, methods of detection, diagnosis and appropriate treatment to achieve control. It is considered a public health problem due to its prevalence, high cost of treatment and because it affects people's quality of life $\mathrm{A}^{4,6}$.

From a chemical point of view, caries lesions are the result of sugar metabolism carried out by biofilm that produce acids, mainly lactic acids, this lowers the $\mathrm{pH}$ of the biofilm, creating conditions of sub-saturation and demineralization, normally counteracted by remineralization phenomena. This process is always present in the oral cavity and is part of the physiological processes if the balance between demineralization and remineralization is maintained. Otherwise, if the imbalance, in favor of demineralization, is maintained over time, the loss of minerals can progressively destroy the dental tissues, generating pain, abscesses and

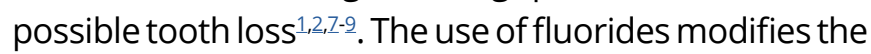
caries-cariogenic diet relationship, delaying cavitation, allowing to protect the dental structure and tolerating a diet with more carbohydrates by lowering the critical pH from 5.5 to 4.5. However, if carbohydrate levels are very high it does not prevent cavitation of the lesions 1,2,7,,10.

It is a complex, chronic and multifactorial disease with a high prevalence that, in general, has not been given sufficient importance. It is the result of the interaction between the dental structure with the biofilm formed on the dental surface, dietary carbohydrates, saliva and genetic influences, among others. The current understanding also involves behavioral, social, and psychological factors in the expression of the disease at the individual level12,8,11-13.

Various protective and risk factors are involved

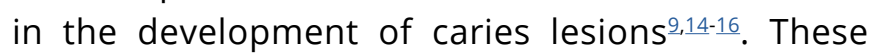
factors include the social determinants of health, which the World Health Organization $(\mathrm{WHO})^{17}$ defines as «the circumstances in which people are born, grow, live, work and age, including the health system». These circumstances are the result of the distribution of money, power and resources at the global, national and local levels, which in turn depend on the policies adopted.
All teeth are susceptible to caries lesions throughout life, beginning with coronary exposure and subsequently with root surfaces exposure when gingival recessions occur. The disease process depends on various factors such as the location, morphology, structural composition and time of the teeth in the mouth, for example, the occlusal morphology of the deciduous teeth presents fossae and fissures conducive to the formation and retention of biofilm and/or food, reason why they are more susceptible to generate caries lesions $9,16,18$. The presence of biofilm is an essential factor for the formation of caries lesions; however, its presence is not in itself sufficient to develop the disease due to its multifactorial nature ${ }^{9,19}$.

At an early, subclinical stage, the enamel presents a direct dissolution and softening of the surface, generating a structural opening that is a means of diffusion, resulting in the demineralization continuing towards the interior of the enamel where the demineralization rate in the subsurface zone is greater than in the superficial zone, generating the first manifestation of caries disease known as «white spot» which is not yet cavitated and is reversible through changes in hygiene and diet habits, or fluoride application. The surface enamel is relatively intact, due to the constant precipitation of minerals from saliva or external minerals such as toothpastes and/ or mouthwashes. This process of demineralization deep in the enamel can occur for weeks, months, or years before cavitation occurs, and may even never lead to cavitated lesion?,20.

This current understanding of caries disease allows the detection of caries lesions at an early, noncavitated stage, and a risk assessment to generate prevention, appropriate treatments, and to establish the frequency of controls. For this reason, it is essential to count caries indexes with the ability to detect these early manifestations of caries lesions, which the decay - missing - filled in deciduous teeth (dmft) or Decay - Missing - Filled in permanent teeth (DMFT) index does not allow? 9 .

Diagnosis is a complex and fundamental cognitive process to carry out an adequate treatment based on the patient's needs. It consists of collecting data, signs and symptoms to analyze and interpret them, concluding in a condition or pathology. It is essential that it be performed prior to any clinical action to choose the best treatment and thus have a better prognosis. 
Caries lesion detection is a process that determines whether the disease is present using an objective method or system. Efforts have now been made to improve the diagnostic process for caries disease and to make treatment decisions for it; for this reason, more than 29 systems have been created for its detection, examples of which are the dmft/DMFT index, International Caries Detection and Assessment System (ICDAS) or Nyvad, among others. Of these, the most widely used worldwide and by the WHO is the dmft/DMFT index, although it must be considered that the current approach to caries diagnosis is based on individual risk, analyzing the presence of caries lesions and the risk and protective factors present ${ }^{2}$.

The $\mathrm{dmft} / \mathrm{DMFT}$ index has been used for over 70 years. This index shows the caries history of a person or group of them (Chart 1).

Chart 1. dmft/DMFT index

\begin{tabular}{|l|l|}
\hline \multicolumn{1}{|c|}{ dmft (deciduous teeth) } & \multicolumn{1}{|c|}{ DMFT (permanent teeth) } \\
\hline $\begin{array}{l}\text { decayed: cavitated carious lesions with exposed dentin. } \\
\text { missing: tooth lost due to caries. }\end{array}$ & $\begin{array}{l}\text { Decayed: cavitated carious lesions with exposed dentin. } \\
\text { filled: tooth with a restoration. }\end{array}$ \\
& $\begin{array}{l}\text { Missing: tooth lost due to caries. } \\
\text { Filled: tooth with a restoration. }\end{array}$ \\
\hline
\end{tabular}

This index provides a quick look at how the tooth has been affected by caries, but it does not incorporate a preventive look, as it does not detect lesions in early stages, being able to underestimate the presence of caries lesions, which limits the possibility of understanding the true oral health situation regarding dental caries ${ }^{21-25}$.

The examination for the DMFT index is performed on 28 permanent teeth, excluding the third molars or also for the 32 permanent teeth, as defined in the third edition of the WHO "Oral Health Surveys - Basic Methods" in 1987. From the same Thus, for temporary teeth, the $\mathrm{dmft}$ index evaluates a maximum of 20 teeth, corresponding to deciduous teeth. To obtain the result of these indexes, all the variables are added together and the result indicates the number of recent and/or past caries injuries, that is, the person's caries history. For both the dmft and DMFT index, if a tooth has a carious lesion and is filled, the most serious criterion is considered to be "decayed" 23,24 .

The International Caries Detection and Assessment System, ICDAS, is a more recent visual method and seeks to detect caries lesions in their earliest stages, although it also includes cavitated lesions. It began to be developed in 2002 during the International Consensus Workshop on Caries Clinical Trials (ICW-CCT) and in 2005 it was agreed upon as ICDAS II. ICDAS is a standardized system based on the best available evidence that assesses both the presence of caries lesions and their severity from initial and reversible states to cavitated lesions, classifying in increasing severity codes from 0 to 6 , as detailed in chart 2,,9,26-29.

Chart 2. ICDAS detection codes

\begin{tabular}{|c|l|}
\hline ICDAS & \multicolumn{1}{|c|}{ Description } \\
\hline ICDAS 0 & Sound tooth surface, no evidence of caries. \\
\hline ICDAS 1 & $\begin{array}{l}\text { First visual change in enamel, visible opacity or discoloration (white and/or brown lesion) only visible on a } \\
\text { dry tooth surface. }\end{array}$ \\
\hline ICDAS 2 & $\begin{array}{l}\text { Distinct visual change in enamel, visible opacity or discoloration (white and/or brown lesion) visible on a wet } \\
\text { tooth surface. }\end{array}$ \\
\hline ICDAS 3 & $\begin{array}{l}\text { Localized enamel breakdown due to caries with no visible dentin or underlying shadow, white and/or brown } \\
\text { lesion. }\end{array}$ \\
\hline ICDAS 4 & $\begin{array}{l}\text { An underlying dark shadow from dentin with or without localized enamel breakdown. The shadow } \\
\text { appearance is often seen more easily when the tooth is wet. }\end{array}$ \\
\hline ICDAS 5 & $\begin{array}{l}\text { Distinct cavity with visible dentin in opaque or discolored enamel. Affects up to half of the evaluated } \\
\text { surface. }\end{array}$ \\
\hline ICDAS 6 & $\begin{array}{l}\text { Extensive distinct cavity with visible dentin in opaque or discolored enamel. Affects more than half of the } \\
\text { evaluated surface. }\end{array}$ \\
\hline
\end{tabular}


On the other hand, ICDAS evaluates the activity of caries lesion, differentiating active and inactive lesions, independent of the severity code, which allows making a more precise and personalized diagnosis and treatment for the patient based on risk, this because, regardless of the severity of the lesion, not all will have the same treatment since it also depends on the activity of the caries lesion. In this way, the prognosis of the tooth is improved by avoiding over-treatment or under-treatment, for example, in noncavitated lesions, which are not detected by the dmft/DMFT index. Although the activity of the lesion is classified as active or inactive, its characteristics depend on the severity of the lesion as observed in chart 326,30.

Chart 3. Activity of caries lesion detected with ICDAS

\begin{tabular}{|l|l|l|l|}
\hline \multicolumn{2}{|c|}{ Active lesion } & \multicolumn{1}{c|}{ Inactive lesion } \\
\hline \multicolumn{1}{|c|}{ ICDAS } & \multicolumn{1}{|c|}{ Features } & \multicolumn{1}{c|}{ ICDAS } & \multicolumn{1}{c|}{ Features } \\
\hline $\begin{array}{l}\text { ICDAS 1, 2, } \\
3 \text { y 4 }\end{array}$ & $\begin{array}{l}\text { Enamel surface with white / yellowish and opaque } \\
\text { lesion. Rough surface when using a blunt tip probe } \\
\text { without pressure. The lesion is in an area of } \\
\text { accumulation of biofilm such as pits or fissures, grooves, } \\
\text { gingival margin, below or above the point of contact. } \\
\text { There may be a biofilm in the lesion. }\end{array}$ & $\begin{array}{l}\text { ICDAS } \\
1,2,3 \\
\text { y 4 }\end{array}$ & $\begin{array}{l}\text { Enamel surface with shiny lesion of } \\
\text { white, brown or black color. The enamel } \\
\text { feels hard and smooth when using the } \\
\text { blunt tip probe without pressure. There } \\
\text { may be an absence of biofilm in the } \\
\text { lesion. }\end{array}$ \\
\hline ICDAS 5Y 6 & $\begin{array}{l}\text { Dentin feels soft or leathery when probing with a blunt- } \\
\text { tip probe without pressure. There may be a biofilm in } \\
\text { the lesion. }\end{array}$ & $\begin{array}{l}\text { ICDAS } \\
5 \text { Y 6 }\end{array}$ & $\begin{array}{l}\text { Dentin is shiny and hard when using a } \\
\text { blunt tip probe without pressure. There } \\
\text { may be an absence of biofilm in the } \\
\text { lesion. }\end{array}$ \\
\hline
\end{tabular}

An active lesion presents a greater probability of changing its state, that is, of progressing, stopping or reversing, than an inactive lesion since it presents an increase in dynamic activity in terms of mineral movement. In contrast, an inactive lesion is less likely to change state than an active lesion since it presents less movement of minerals, and the lesion is more likely to remain with the same severity ${ }^{30}$.

\section{Objectives}

The research question asked was: Are there differences in sensitivity and specificity in caries detection when using the ICDAS and dmft/DMFT indexes? The main objective of the investigation is to evaluate if there are differences in the sensitivity and specificity in the detection of caries using the ICDAS and dmft/DMFT indexes.

\section{Materials and methods}

To answer the research question, a qualitative systematic review was carried out on the $\mathrm{dmft} / \mathrm{DMFT}$ and ICDAS caries indexes. The inclusion criteria were those studies in Spanish and English, descriptive and experimental, with results under the dmft/DMFT and ICDAS indexes, in vivo and ex vivo, and that were conducted in humans. Exclusion criteria were studies older than 7 years and gray literature.

A search for caries lesion detection systems using dmft/DMFT index and ICDAS was performed in the Medline, ClinicalKey and SciELO databases. The key words used were Dental caries, DMF index, Dental health surveys, Sensitivity and specificity. Statistical analysis was not performed due to the nature of the review. 
The search showed 3,581 articles, of which 2,304 were discarded for their year of publication, 159 for the language, 432 for not being human, 665 articles for their title and abstract. A total of 21 articles were read, of which 14 were included in the study because they met the inclusion and exclusion criteria. For each of the selected articles, a critical evaluation of the literature was carried out. The analyzed studies consisted of 2 randomized clinical trials and 12 cross-sectional studies. Of these, 7 were in vivo, 2 ex vivo and 5 in vivo and ex vivo. Of the 14 studies, 14 had a defined methodology and inclusion and exclusion criteria, and 13 studies had defined objectives.

Most of the selected studies come from Brazil, where 753 people with ages ranging from 3 to 14 years were studied, from Asian countries where 2,995 people with ages ranging from 3 to 11 years were studied; and from European countries where 109 people with ages ranging from 2 to 55 years were studied.

\section{Results}

The sensitivity of the dmft/DMFT index had a variation in studies between $69.8 \%$ and $73.2 \%$. The sensitivity of ICDAS varied in the different studies from $55 \%$ to $98.7 \% \frac{131-35}{}$. Moreover, the specificity of the dmft/DMFT index had a variation of $69 \%^{1,36}$. Finally, the specificity for ICDAS varied from $69 \%$ to $100 \%^{1,31-35}$ (Chart 4).

Chart 4. Sensitivity and specificity between ICDAS and dmft/DMFT according to the articles analyzed

\begin{tabular}{|c|c|c|c|c|c|}
\hline \multicolumn{2}{|c|}{ Sensitivity } & \multicolumn{3}{c|}{ Specificity } \\
\hline Article & ICDAS & dmft/DMFT & Article & ICDAS & dmft/DMFT \\
\hline Bhoopathi PH, et al. & $98.7 \%$ & $69.8 \%$ & Freitas LA, et al. & $73 \%$ & - \\
\hline Freitas LA, et al. & $55 \%$ & - & Iranzo-Cortés JE, et al. & $79.1 \%$ & - \\
\hline Iranzo-Cortés JE, et al. & $82 \%$ & - & Nogueira VK, et al. & $100 \%$ & - \\
\hline Nogueira VK, et al. & $88.5 \%$ & - & Qudeimat MA, et al. & $74 \%$ & - \\
\hline Qudeimat MA, et al. & $73.5 \%$ & - & Singh R, et al. & $79.8 \%$ & - \\
\hline Singh R, et al. & $79,8 \%$ & - & Teo TK, et al. & $69.3 \%$ & - \\
\hline Teo TK, et al. & $86.3 \%$ & - & Wang SS, et al. & - & $69.4 \%$ \\
\hline Wang SS, et al. & - & $73.2 \%$ & & & \\
\cline { 1 - 3 }
\end{tabular}

Like any visual method, it is extremely important to have a good visualization of the teeth because proximal caries lesions are one of the most difficult lesions to detect early. In addition, it is not possible to detect it early with the $\mathrm{dmft/DMFT} \mathrm{index} \mathrm{unless} \mathrm{the} \mathrm{adjacent} \mathrm{tooth} \mathrm{is} \mathrm{missing} \mathrm{or} \mathrm{presents} \mathrm{a} \mathrm{cavitated} \mathrm{lesion} \mathrm{with} \mathrm{exposed} \mathrm{dentin.} \mathrm{For} \mathrm{this}$ reason, when analyzing the specificity and sensitivity in the detection of proximal caries and free smooth surface caries with ICDAS, the values are lower when analyzing the proximal faces than in the free smooth surface ${ }^{31}$.

Examination of proximal surfaces in posterior teeth is complex due to low visualization, which determines low sensitivity and specificity in an important location for the generation of caries lesions. Currently, the gold standard for detecting proximal lesions is Bitewing radiography with a sensitivity of $49 \%$ and a specificity of $79 \%$. An alternative is the use of orthodontic separators to achieve a direct view of the proximal surfaces; one study analyzed the sensitivity and specificity with and without the use of these separators. The sensitivity of ICDAS before dental separation was $55 \%$ and the specificity was $73 \%$, values after tooth separation for sensitivity were $88 \%$ and $26 \%$ for specificity. After tooth separation, the sensitivity improved considerably, exceeding the gold standard and ICDAS before tooth separation, but the specificity decreased. For this reason, caution should be exercised due to the possibility of obtaining false positives and generating overtreatment ${ }^{31}$. 
When comparing the prevalence of caries with the DMFT and ICDAS indexes, a higher prevalence of healthy teeth is observed using DMFT achieving $96.2 \%$ compared to ICDAS, which achieved $90.6 \%$. The prevalence of carious teeth was higher with ICDAS obtaining $7.8 \%$ compared to DMFT, which obtained $2.2 \%$ with statistically significant differences using the chi-square test. The same analysis in deciduous teeth showed a higher prevalence of healthy teeth using the dmft index obtaining $80.6 \%$ compared to ICDAS, which achieved $75.8 \%$ of healthy teeth. The prevalence of carious teeth was higher with ICDAS registering $17.1 \%$ compared to $\mathrm{dmft}$ that registered $12.2 \%$ with statistically significant differences ${ }^{7}$. According to a study by Castro ALS, et al., ICDAS showed $75 \%$ of decayed teeth and $28.1 \%$ for DMFT. The average number of decayed, missing and filled teeth was 6.0 according to DMFT, 6.2 according to ICDAS. When the disease extension was analyzed for DMFT it was $22.12 \%$ and for ICDAS it was $49.11 \%$ 군.

According to an investigation by Melgar RA, et al., whose study subjects were 150 children and 150 mothers of the children studied from 20 primary health services in Brazil, $86 \%$ of the mothers had at least one type of restoration and $25.4 \%$ had at least one tooth extracted by caries; $16.6 \%$ of the mothers presented cavitated lesions and $80.6 \%$ noncavitated. $60 \%$ of children had noncavitated lesions (32\% women; $28 \%$ men) classified according to ICDAS as codes 1 and 2, and 31.3\% (16.6\% women; $14.6 \%$ men) had lesions cavitated classified by ICDAS as codes 3, 4, 5 and 6 . In the mothers, ICDAS did not show a statistically significant difference from DMFT since most mothers had cavitated lesions that had been restored or a history of teeth extracted due to caries. Detection of noncavitated lesions significantly influenced respect to dmft/DMFT in children4.

Potlia I, et al., in their comparison study between DMFT and ICDAS found similar results to the other studies. In a population of 253 patients, the average DMFT was 2.29 and it was observed that $50.66 \%$ of the patients had decayed teeth, $45.33 \%$ filled, and only $3.33 \%$ missing due to caries. When evaluated with ICDAS, 54\% had cavitated carious lesions and $84 \%$ had noncavitated lesions; all subjects had at least one nonintact tooth surface. $64 \%$ of the patients had filled teeth and $6 \%$ had missing teeth, reflecting that when using ICDAS a greater number of caries lesions was registered. In this study, of the 253 patients, 212 patients presented noncavitated caries lesions which are not considered with the DMFT index and which could be treated preventively avoiding tissue destruction and the costs of their rehabilitation ${ }^{5}$.

\section{Discussion}

The limitations faced in this study were the languages and the antique of the studies, which was determined by the inclusion and exclusion criteria, which could generate a bias with respect to the information that was not accessed. On the other hand, the studies analyzed present limited and controlled populations, which does not represent reality. Furthermore, most of the population studied are children, with scarce data in adults, which limits the applicability of the results. These limits in the analyzed population can cause bias.

A health indicator is a public health surveillance tool that defines a measure of health, for example, the occurrence of a disease or other related event. It allows the generation of evidence on the status and trends of the health situation of a population, including documentation of inequities, evidence that should serve as a basis for determining the most underprivileged groups in health, the stratification of epidemiological risk and the identification of critical areas as a basis for establishing policies and priorities in this area. Because of this, it is essential to choose an adequate index to assess the population reality ${ }^{38}$.

In literature, in vivo studies comparing the $\mathrm{dmft} /$ DMFT and ICDAS indexes are scarce, only finding isolated studies with a population not representative of the indexes individually. Furthermore, the existing studies are very heterogeneous in nature, which makes their analysis and comparison difficult.

Caries is one of the most frequent chronic diseases in the population, therefore, it is important to prevent it and make an early diagnosis. It is at this point that the importance of using the best available index must be considered, but the population analyzed in the existing studies belongs to very restricted age groups, which can produce a bias in the results due to the fact that, at different stages of life, it is possible to find, to a greater or lesser extent, caries lesions with different severities and the caries indexes studied have different sensitivity and specificity, depending on the severity of the lesion. 
Sensitivity and specificity values may vary between studies, as reported, visual methods for caries detection have low sensitivity, but high specificity ${ }^{39}$; This is because they are subjective methods that depend on clinical experience, knowledge and training with the index used ${ }^{32}$. For this reason, ICDAS presented a wide variation in sensitivity, $55 \%$ and $98.7 \%$, and specificity, $69 \%$ and $100 \% 1,2,31-35$, unlike $\mathrm{dmft} / \mathrm{DMFT}$ that presented a sensitivity between $69.8 \%$ and $73.2 \%$ and a specificity of $69 \% 1,36$. This is believed to be due to the fact that ICDAS is made up of a range of stages of the caries lesion greater to that of dmft/DMFT, but that in many occasions present specific differences between them, which hinders their proper use, especially in inexperienced dentists, which can affect the results in studies if they are carried out by people without experience in the use of ICDAS, unlike the dmft/ DMFT index that only considers cavitated lesions with exposed dentin, restored or missing due to caries, which facilitates a more uniform approach among professionals who use it.

Most of the epidemiological studies in dentistry are performed in children and the index used in the vast majority is dmft/DMFT. A big problem in using an index that only evaluates cavitated lesions with exposed dentin is that it categorizes as ill only a person where the only possible treatment is invasive ending in an operative treatment or a surgical procedure. Considering that the first experiences are fundamental to determine the future behavior of individuals, and submitting a child to an invasive procedure can condition dental care, the future behavior and relationship with the dentistry of that person, only to treat a manifestation of the disease instead of treating chronic disease as such. On the other hand, if the population were analyzed using an index with an ability to detect lesions in early stages, allowing non-invasive and/or minimally invasive actions to be carried out during the first dental approaches in childhood, it is possible to generate a better relationship between the child and dentistry, being able to promote greater adherence to dental treatment, treat the disease, raise awareness by not traumatizing during dental care and perform less expensive treatments, where invasive treatments are only indicated for certain specific situations, where the above failed ${ }^{4}$.
The biggest problem of ICDAS is its greater economic cost and the time that its application entails, because it needs a previous prophylaxis of the dental surfaces, light, dental mirror and compressed air to dry the teeth at the time of the examination. Instead, dmft/ DMFT only needs a dental mirror, light and dental cotton rolls $s^{4,5,37}$. ICDAS requires more clinical time for its execution, taking approximately $265.88 \pm 21.43^{5}$ $534^{37}$ seconds per patient, while the $\mathrm{dmft} / \mathrm{DMFT}$ index takes $145.46 \pm 17.6^{5}-228^{37}$ seconds per patient.

Although the sensitivity of the $\mathrm{dmft} / \mathrm{DMFT}$ and ICDAS indexes is variable, only one study compared them, resulting in the $\mathrm{dmft} / \mathrm{DMFT}$ index with a sensitivity of $69.8 \%$ and ICDAS of $98.7 \%^{1}$. Otherwise, the specificity between the dmft/DMFT index and ICDAS was not directly compared in any study. This shows the scarce existing literature on the comparison between both indexes.

In South America, the reality is disparate, the most recent studies are between 1994 and 2015, so not all countries have updated data that can represent their reality ${ }^{40,41}$. The average DMFT index for 12-year-old children in Latin America is 2.540,41 where the country with the highest DMFT index is Ecuador with an index of 4.9 and the country with the lowest index, Trinidad and Tobago with a 0.640,41. Worldwide the average 12year DMFT index is 1.9. For example, countries such as the United Kingdom and Germany have indexes of 0.5, Poland with a DMFT index of 2.8 or Brazil with $1.3^{41}$.

However dmft/ DMFT index does not represent the reality of oral health as it only detects cavitated lesions with exposed dentin. For example, Chile's official 12year DMFT index is 1.9, however, studies with a larger population and with a greater age range show that in the 35-44 age group the DMFT index increases considerably to 15.1 and in the age group of $65-74$ years is 21.6. In addition, other studies show a high prevalence of caries lesions, in groups between 2 4 years a prevalence of $45.9 \%$ has been seen using ICDAS, or in age groups between 25 to 82 years where almost $100 \%$ of the studied population is affected, using the DMFT index. This incredible mutilation is because noncavitated caries lesions are not detected or treated appropriately and early, generating underdiagnosis and under-treatment $20,42,43$. 
For this reason, it is essential to choose the indicator that gives us the most information early. When the dental examination is carried out using ICDAS, the five dental surfaces must be examined and its great benefit is that it allows detecting lesions in their initial stages where only the enamel is affected and it is still a reversible process, allowing non-invasive maneuvers to be performed to preserve the dental structure, stopping the progression of the caries lesion, favoring the remineralization of the lesion and allowing to increase the life expectancy of the teeth. This is because when cavitating and restoring a tooth, it enters a degenerative and irreversible process where from time to time it will be necessary to carry out a replacement of the restoration, longevity dependent on the restoration material and its technical sensitivity together with the technical consciousness at the time of restoration, which leads to a greater loss of tooth structure until reaching a point where it is not possible to keep the tooth in the mouth $=26-30$.

One of the limitations of ICDAS, in addition to the greater clinical time and resources required, is the learning curve which is greater than in the $\mathrm{dmft} /$ DMFT index. Nogueira VK, et al., demonstrated that the greater the clinical experience and knowledge the specificity and sensitivity of ICDAS increases, furthermore, it was found that the stages of ICDAS are easier to understand by people with little experience than other caries indices due to their similarity in various parameters with $\mathrm{dmft} / \mathrm{DMFT}$ and for following a progression of the lesion ${ }^{33}$. According to the study by Qudeimat MA, et al., General dentists when using ICDAS tend to identify teeth as decayed when they are sound as opposed to a specialist, this is explained by the lesser experience and knowledge related to the index 139 .

As is known, an important element to consider when using ICDAS is the operator's experience. Examiners who were undergraduate and postgraduate students were evaluated creating two groups that underwent ICDAS training, were evaluated before the training, on the day of the training and two years after the training. In this case the undergraduate students had a sensitivity of $85 \%$ and a specificity of $66 \%$ in the first evaluation, unlike the graduate students who had a sensitivity and specificity of $85 \%$, these results in favor of the postgraduate students suggest that greater clinical experience influences caries evaluation. These results were consistent with those found in the second and third evaluations, where both undergraduate and postgraduate students had an improvement in their evaluations, reaching a sensitivity of $94 \%$ and a specificity of $93 \%$ in undergraduate students and a sensitivity $97 \%$ and a specificity of $93 \%$ for postgraduate students 2 years after training. These results confirm that training, knowledge and clinical practice help improve caries detection with visual methods ${ }^{33}$.

According to Singh $\mathrm{R}$, et al., and Teo TK, et al., when comparing the visual methods in vivo with the in vitro, which corresponds to the Gold Standard considered histological method, it was determined that the in vitro results are extrapolated to the results in vivo, this reinforces the precision that can be achieved by using ICDAS to detect carious lesions ${ }^{34,35}$. This is concluded because ICDAS sensitivity in vivo was between $75 \%$ and $95 \%$; specificity was between $61 \%$ and $86 \%$. In vitro sensitivity was between $81 \%$ and $91 \%$; the specificity was between $61 \%$ and $85 \%$ where there were no statistically significant differences between the results in vivo and in vitro. ICDAS has good repeatability ranging in vivo between $68 \%$ and $79 \%$ and in vitro between $72 \%$ and $100 \% 34,35$. Furthermore, ICDAS exhibited the highest sensitivity and specificity of visual methods, along with being more accurate than bitewing radiography in detecting occlusal lesions limited to enamel and obtaining similar performance in occlusal dental caries lesions 2,34 .

On the other hand, a major problem in detecting caries lesions early is the proximal surfaces since they present great difficulty for clinical evaluation. A study by Freitas LA, et al., Compared the sensitivity and specificity of ICDAS before and after performing a temporary dental separation with orthodontic bands; which were placed for a week; with bitewing radiographs which are standardized and frequently used for the evaluation of proximal surfaces. Like any visual method, it is of utmost importance to have a good vision of the surface, for this reason the results after dental separation with orthodontic bands were better, obtaining greater sensitivity, improving from $55 \%$ to $88 \%$, and a higher precision, but the specificity decreased considerably from $73 \%$ to $26 \%$, being able to obtain false positives and generate overtreatment. 
This is explained because having direct vision of the proximal surfaces can detect incipient lesions that were considered healthy without dental separation. But it should be considered that temporary dental separation has its complications such as the need for two sessions to examine the proximal surface, discomfort due to the orthodontic band and the possible local gingival inflammation that the band can cause, in addition to not benefiting the people with low cariogenic risk. When they compared the sensitivity and precision of ICDAS after dental separation with bitewing radiography, they found that the results were better in ICDAS, presenting an excellent agreement between both methods ${ }^{2,31}$.

As previously demonstrated, dental caries is a chronic disease that generates damage that can be accumulated over time, for this reason adults generally have more extensive and more severe lesions than children. Melgar RA, et al., studied children and their mothers and compared the dmft/DMFT and ICDAS index and their results are consistent with the manifestation of a chronic disease, in the mothers there were no statistically significant differences between both indexes, this is explained because having more severe lesions, which are detected equally with both indexes. On the other hand, in children there were statistically significant differences because incipient or less severe lesions are more frequent and are not detected by the dmft/DMFT index, which it generates an underestimation of the disease in children, losing much information ${ }^{4}$. It is for this reason that in children it has a greater benefit to use ICDAS because it presents a greater cost-effectiveness and in adults its use can be analyzed according to the available resources since its cost-effectiveness is lower.

For this reason, it is important to consider the use of ICDAS in children since, anatomically, the enamel of the deciduous teeth is thinner and more porous, and has a lower mineral content than the permanent teeth, determining a progression of the caries lesion more rapid, being another reason to use an index that is capable of detecting lesions in early stages in children avoiding their rapid progression ${ }^{34}$.

ICDAS and dmft/DMFT share some stages, specifically those with exposed dentin. Generally, the point of coincidence between both indexes is ICDAS 3 and in other cases it is considered ICDAS 4, what is not standardized and continues to generate debate in studies that compare both indexes since there is no equivalence point, therefore it is not correct convert ICDAS results to dmft/DMFT 1 . 5 . Inter-examiner variation varies more in ICDAS than in $\mathrm{dmft} / \mathrm{DMFT}$ because it is an index where the knowledge, clinical experience and training determine the specificity and sensitivity of the index and in the studies of more than one examiner these do not present the same knowledge nor experience. For this reason, there is a general perception among examiners that ICDAS is more cumbersome than the $\mathrm{dmft} / \mathrm{DMFT}$ index and more difficult to use in a large-scale epidemiological study, although it is able to detect, in a statistically significant way, a greater number of lesions with respect to $\mathrm{dmft} / \mathrm{DMFT} 1,39$.

A great benefit of using ICDAS, unlike the $\mathrm{dmft/DMFT}$ index, in addition to detecting noncavitated lesions, is that it is also capable of detecting active and inactive caries lesions, which determines different therapeutic options for each case. In addition, it evaluates dental losses due to different causes, including caries, so in the final count, extractions for orthodontic indication, for example, are also considered. Finally, ICDAS also records restorations due to caries and other causes such as fractures, closure of diastema, aesthetic reasons, among others, so that the final record is more detailed, which determines that a higher valuation is obtained than using the dmft/DMFT index ${ }^{5}$.

\section{Conclusion}

In answer to the research question of the present work, ICDAS is the caries index that presents greater sensitivity and specificity compared to the dmft/ DMFT index. According to Potlia l, et al., it provides $43 \%$ more information regarding the dmft/DMFT index, which improves the diagnosis, prognosis and treatment plan ${ }^{1,237}$, however, it requires more clinical time for its execution. For this reason, the $\mathrm{dmft} /$ DMFT index provides less information, but with a lower economic, logistical and time cost ${ }^{5,37}$. For these reasons, the dmft/DMFT index continues to be the choice for epidemiological studies where the time available for the examination, due to the size of the sample analyzed, and the resources available make it the best option to the detriment of ICDAS 4,5 . 
Using the dmft/DMFT index, instead of ICDAS, in children causes a lot of important information to be lost because most of the lesions are noncavitated, underestimating the presence of the disease in its most frequent presentation in children, especially for make decisions ${ }^{4}$. The inclusion of noncavitated lesions improves sensitivity, especially in a low prevalence population; this early detection is a challenge in diagnosis $s^{4,7}$.

ICDAS used correctly has a sensitivity and specificity superior to $\mathrm{dmft/DMFT1,2,31-36}$, in addition to allowing carious lesions to be detected in early stages, favoring preventive treatment, noninvasive treatment and/ or minimally invasive treatment and not only put emphasis on restorative dentistry treating caries lesion and not the disease, but also promote changes in habits and raise awareness in people who are subjected to noninvasive and/or minimally invasive therapies, emphasizing treating the disease to reach a state of health and thus treating the injury ${ }^{9}$. On the other hand, it allows performing procedures at a lower cost, which in the long term can contribute to improving the oral health of the population, which is demonstrated in existing studies that report that $100 \%$ of the population studied presents caries and has been An average DMFT index in adults between 3.76 - 22.16, 62,42,44-46 has been described.

Further comparative studies between ICDAS and the dmft/DMFT index should be conducted to demonstrate differences in the specificity, sensitivity, and detection of caries lesions by studying representative populations, because the caries assessment studies that have been conducted are with limited populations and not representative of reality, allowing to modify the index used in epidemiological studies in favor of ICDAS, which would demonstrate the true reality of oral health in the world population.

\section{Competing interests}

No financial, legal or political competing interests with third parties (government, commercial, private foundation, etc.) were disclosed for any aspect of the submitted work (including but not limited to grants, data monitoring board, study design, manuscript preparation, statistical analysis, etc.).

\section{References}

1. Bhoopathi PH, Patil PU, Kamath BV, Gopal D, Kumar S, Kulkarni G. Caries detection with ICDAS and the WHO criteria: a comparitive study. J Clin Diagn Res. 2017;11(12): 9-12. doi: 10.3390\%2Fijerph16214120

2. Cerón-Bastidas XA. El sistema ICDAS como método complementario para el diagnóstico de caries dental. Rev CES Odont. 2015;28(2):100-109.

3. Kassebaum NJ, Bernabé E, Dahiya M, Bhandari B, Murray CJL, Marcenes W. Global burden of untreated caries: a systematic review and metaregression. J Dent Res. 2015;94(5):650-658. doi: 10.1177/0022034515573272

4. Melgar RA, Pereira JT, Luz PB, Hugo FN, Araujo FB. Differential impacts of caries classification in children and adults: a comparison of ICDAS and DMF-T. Braz Dent J. 2016;27(6):761-766. doi: $10.1590 / 0103-6440201600990$

5. Potlia I, Kumar PGN, Prashant GM, Sushanth VH, Imranulla M, Mallick $S$ et al. Comparison of the caries status using dmft, ICDAS II and cast index system. Int J of Adv Res. 2016;4(10):364-371. doi: $\underline{10.21474 / \| \text { AR01/1800 }}$

6. Urzúa I, Mendoza C, Arteaga O, Rodrígues G, Cabello R, Faleiros $S$ et al. Dental caries prevalence and tooth loss in chilean adult population: first national dental examination survey. Int J Dent. 2012; 2012: 810170. doi: 10.1155/2012/810170

7. Ferraz EG, Silva LR, Sarmento VA, Campos EJ, Oliveira TFL, Magalhães JC et al. Comparison of two visual methods for detecting caries among obese and non-obese children. Acta Odontol Scand. 2016;74(5):405-10. doi: 10.3109/00016357.2016.1169555

8. Olivan SRG, Deana AM, Pinto MM, Sfalcin RA, Fernandes KPS, Mesquita-Ferrari RA et al. Diagnosis of occlusal caries lesions in deciduous molars by coherent light scattering pattern speckle. Photodiagnosis Photodyn ther. 2017;18:221-225. doi: 10.1016/j. pdpdt.2017.03.004

9. Pitts NB, Zero D. White Paper on dental caries prevention and management - a summary of the current evidence and the key issues in controlling this preventable disease. FDI World Dental Federation [Internet]. 2016. Available from: https://www. fdiworlddental.org/sites/default/files/media/documents/2016fdi_cpp-white_paper.pdf

10. Sheiham A, James WPT. Diet and Dental Caries: The Pivotal Role of Free Sugars Reemphasized. J Dent Res. 2015;94(10):13411347. doi: $10.1177 / 0022034515590377$

11. Fejerskov O. Concepts of dental caries and their consequences for understanding the disease. Community Dent Oral Epidemiol. 1997;25(1):5-12. doi: 10.1111/j.1600-0528.1997.tb00894.x 
12. Reisine S, Litt M. Social and psychological theories and their use for dental practice. Int Dent J. 1993;43(3):279-287.

13. Selwitz RH, Ismail Al, Pitts NB. Dental caries. Lancet. 2007;369(9555):51-59. doi: 10.1016/S0140-6736(07)60031-2

14. Featherstone JDB. The continuum of dental caries-evidence for a dynamic disease process. J Dent Res. 2004;83(1):39-42. doi: $10.1177 / 154405910408301$ s08

15. Pitts NB. A review of the current knowledge of the progress of approximal lesions. In: Scientific proceedings of the 10th Asian Pacific Dental Congress, 26th-31st March 1981; Singapore: Singapore Dental Association; 1983.

16. Zero DT. Dental caries process. Dent Clin North Am. 1999;43(4):635-664.

17. Organización Mundial de la Salud (OMS). Determinantes sociales de la salud. [Internet]. 2010. [accessed in 2020 May]. Available from: http://www.who.int/social_determinants/es/

18. Hara AT, Zero DT. The caries environment: saliva, pellicle, diet, and hard tissue ultrastructure. Dent Clin North Am. 2010;54(3):455-467. doi: 10.1016/j.cden.2010.03.008

19. Aas JA, Griffen AL, Dardis SR, Lee AM, Olsen I, Dewhirst FE et al. Bacteria of dental caries in primary and permanent teeth in children and young adults. J Clin Microbiol. 2008;46(4):1407-1417. doi: 10.1128\%2FJCM.01410-07

20. Kidd EAM, Fejerskov O. What constitutes dental caries? Histopathology of carious enamel and dentin related to the action of cariogenic biofilms. J Dent Res. 2004; 83 (1_suppl):35-38. doi: 10.1177/154405910408301s07

21. Agustsdottir $H$, Gudmundsdottir $H$, Eggertsson $H$, Jonsson $\mathrm{SH}$, Gudlaugsson JO, Saemundsson SR et al. Caries prevalence of permanent teeth: a national survey of children in Iceland using ICDAS. Community dentistry and oral epidemiology. 2010;38(4):299-309. doi: 10.1111/j.1600-0528.2010.00538.x

22. Larmas M. Has dental caries prevalence some connection with caries index values in adults? Caries Res. 2010;44:81-84. doi: $10.1159 / 000279327$

23. Nordström M. Caries prevalence DMFT/DMFS. Malmö University [Internet]. 2014. [accessed in 2020 Jun]. Available from: https://www.mah.se/CAPP/Methods-and-Indices/forMeasurement-of-dental-diseases/for-Caries-prevalence/

24. Organización Mundial de la Salud (OMS). Oral Health Surveys: Basic Methods. 5th Ed. [Internet]. Francia: WHO Library; 2013. [accessed in 2020 Jun]. 125p. Available from: http://apps.who.int/iris/ bitstream/handle/10665/97035/9789241548649_eng.pdf;jsessionid=032A35705DA8720585226E73BF9BD10A?sequence $=1$
25. Pitts NB, Chadwick B, Anderson T. Children's Dental Health Survey 2013. Report 2: Dental Disease and Damage in Children England, Wales and Northern Ireland. [Internet]. 2015. [accessed 2020 Jun]. Available from: http://content.digital.nhs.uk/catalogue/ PUB17137/CDHS2013-Report2-Dental-Disease.pdf

26. Pitts NB, Ismail Al, Martignon S, Ekstrand K, Douglas GVA, Longbottom C et al. ICCMSTM Guide for Practitioners and Educators. ICDAS Foundation [Internet]. 2014. Available from: https://www.iccms-web.com/uploads/ asset/5928471279874094808086.pdf

27. Rebolledo BDCB. Estudio de prevalencia, índice significante, severidad de caries y distribución de lesiones por diente y superficie, en niños de 2 a 3 años pertenecientes a jardines infantiles integra de la región metropolitana [tese]. Santiago: Universidad de Chile; 2015.

28. Cruz MFR. Asociación entre lesiones de caries y estado nutricional en niños preescolares de la Región Metropolitana [tese]. Santiago: Universidad de Chile; 2014.

29. Rodrígez G, Cabello R, Urzua I, Reyes M, Faleiros S, Ruiz B et al. Association between body mass index and caries lesions in preschool children in Santiago, Chile. Int J Odontostomat. 2017;11(3):369-375. doi: 10.4067/S0718-381X2017000300369

30. International Caries Detection and Assessment System Coordinating Committee. Rationale and evidence for the International Caries Detection and Assessment System (ICDAS II) [Internet]. 2012. [accessed in 2020 Jun]. Available from: https:// www.iccms-web.com/uploads/asset/5928471279874094808086. pdf

31. Freitas LA, Santos MTBR, Guaré RO, Lussi A, Diniz MB et al. Association between visual inspection, caries activity status, and radiography with treatment decisions on approximal caries in primary molars. Pediatr Dent. 2016;38(2):140-147.

32. Iranzo-Cortés JE, Terzic S, Montiel-Company JM, Almerich-Silla JM, Science LM et al. Diagnostic validity of ICDAS and diagnodent combined: an in vitro study in pre-cavitated lesions. Lasers Med Sci. 2017;32(3):543-548. doi: 10.1007/s10103-017-2146-5

33. Nogueira VKC, Bussaneli DG, Tagliaferro EPS, Spin-Neto $\mathrm{R}$, Escobar A, Cordeiro RCL et al. Examiner's experience and the outcome interpretation of ICDAS and Nyvad's system - a prospective in vitro study. Acta Odontol Scand. 2017;75(3):186190. doi: $\underline{10.1080 / 00016357.2016 .1277260}$

34. Singh R, Tandon S, Rathore M, Tewari N, Singh N, Shitoot AP. Clinical performance of ICDAS II, radiovisiography, and alternating current impedance spectroscopy device for the detection and assessment of occlusal caries in primary molars. J Indian Soc Pedod Prev Dent. 2016;34(2):152-158. doi: 10.4103/09704388.180445 
35. Teo TKY, Ashley PF, Louca C. An in vivo and in vitro investigation of the use of ICDAS, diagnodent pen and cariescan PRO for the detection and assessment of occlusal caries in primary molar teeth. Clin oral investig. 2014;18(3):737-44. doi: 10.1007/s00784-013-1021-4

36. Wang SS, Zhang H, Si Y, Xu T. Analysis of forecasting indexes for dental caries in 3- to 6-year-old children. Chin J Dent Res. 2016;19(3):153-8. doi: 10.3290/j.cjdr.a36680

37. Castro ALS, Vianna MIP, Mendes CMC. Comparison of caries lesion detection methods in epidemiological surveys: CAST, ICDAS and DMF. BMC Oral Health. 2018;18(1):122. doi: 10.1186/s12903018-0583-6

38. Organización Panamericana de la Salud (OMS). Indicadores de salud: Aspectos conceptuales y operativos. [Internet]. 2015. [accessed in 2020 jun]. Available from: https://www.paho.org/ hq/index.php?option=com_docman\&view=download\&category_ slug=health-analysis-metrics-evidence-9907\&alias $=45249$ health-indicators-conceptual-operational-considerations249\&ltemid=270\&lang=es

39. Qudeimat MA, Alomari QD, Altarakemah Y, Alshawaf N, Honkala EJ. Variables affecting the inter- and intra-examiner reliability of ICDAS for occlusal caries diagnosis in permanent molars. J public health dent. 2016; 76(1):9-16. doi: $10.1111 /$ jphd.12105

40. FDI. The Challenge of oral disease. A Call for global action - The Oral Health Atlas [Internet]. 2015 [accessed in 2020 jun]. Available from: https://www.fdiworlddental.org/sites/default/ files/media/documents/complete_oh_atlas.pdf
41. Kassebaum NJ. Dental caries [Internet]. 2016. [accessed in 2020 Jun]. Available from: https://capp.mau.se/dental-caries/

42. Angel P, Fresno MC, Cisternas P, Lagos M, Moncada G. Prevalencia de caries, pérdida de dientes y necesidad de tratamiento en población adulta Mapuche-Huilliche de Isla Huapi. Rev Clin Periodoncia Implantol Rehabib Oral. 2010;3(2):69-72. doi: 10.4067/S0719-01072010000200002

43. Ministerio de Salud de Chile. Análisis de situación de salud bucal en Chile [Internet]. 2010 [Cited 2020 Jun]. 11 p. Available from: https://www.minsal.cl/sites/default/files/files/ An\%C3\%A1lisis\%20de\%20Situaci\%C3\%B3n\%20Salud\%20 Bucal\%20final\%20pdf.pdf

44. Giacaman RA, Reyes PM, Leon VB. Caries risk assessment in chilean adolescents and adults and its association with caries experience. Braz Oral Res. 2013;27(1):7-13. doi: 10.1590/s1806$\underline{83242013000100002}$

45. Rivera PM, Chappuzeau E, Caro JC, Monsalves MJ. Situación de salud oral y calidad de vida de los adultos mayores. Rev Estomatol Herediana. 2012;22(4):197-202.

46. Vargas-Sanhueza V, Muñoz CK, Díaz-Narváez VP, Molina JF. Oral health status in adult population in chile (decayed, missing, filled and permanent tooth): clinical observation at national level. Health. 2015;7(12):1757-1762. doi: 10.4236/health.2015.712191 